\title{
The role of innate lymphoid cells and $T$ helper cell activation in type 2 diabetic patients: a protocol for a systematic review and meta-analysis
}

\author{
Vuyolwethu Mxinwa ${ }^{1 *}$ (D), Tawanda M. Nyambuya ${ }^{1,2}$, Phiwayinkosi V. Dludla $a^{3,4}$ and Bongani B. Nkambule ${ }^{1}$
}

\begin{abstract}
Background: Persistent levels of low-grade inflammation and T lymphocyte activation are associated with insulin resistance and type 2 diabetes that eventually lead to the development of cardiovascular diseases. Interestingly, increasing studies report on an emerging role of innate lymphoid cells in the development of both type 2 diabetes and cardiovascular disease. This systematic review will provide a comprehensive synthesis of available studies reporting on the role of innate lymphoid cells and associated Thelper cell function in type 2 diabetic patients. It will further provide insight into the association of innate lymphoid cell activation and cardiovascular risk in adults living with type 2 diabetes.

Methods: This systematic review protocol has been prepared in accordance with Preferred Reporting Items for Systematic Review and Meta-Analysis Protocols 2015 guidelines. The protocol has been registered with PROSPERO (CRD42018106159). This systematic review and meta-analysis will include published randomised clinical trials, observational studies, and case-control studies. We will also include grey literature. A search strategy will be developed with the help of subject librarian using Medical Subject Heading (MeSH) words for MEDLINE. This will then be adapted for the Embase database. Two independent reviewers VM and BBN will screen all studies using prespecified inclusion and exclusion criteria. The Downs and Black checklist will be used to assess the quality of individual studies. Predefined relevant data items will be extracted using sheets, and all study tables will be created using Review Manager V.5.3. The Grading of Recommendations Assessment, Development and Evaluation approach will be used to assess the strength of evidence.
\end{abstract}

Ethics and dissemination: The review will include publicly available data. The findings of this review will be disseminated through publications.

Keywords: Hyperglycaemia, Glucose metabolism, Inflammation, Innate lymphoid cells, Natural killer cells, T helper cells, Anti-hyperglycemic

\section{Background}

Bing overweight and obesity are existing global health problems, contributing significantly to the rapid rise in metabolic disease-related deaths [1]. Obesity is characterised by excessive fat accumulation and persistent inflammatory response that may interfere with an optimal

\footnotetext{
* Correspondence: 218081787@stu.ukzn.ac.za

'School of Laboratory Medicine and Medical Sciences (SLMMS), College of Health Sciences, University of KwaZulu-Natal, Durban, South Africa
} Full list of author information is available at the end of the article state of health. In an obesity state, adipose tissue (AT) inflammation is associated with elevated levels of adipokines. Th1 and Th17 cytokines are also implicated in the development of type 2 diabetics (T2D) [2-4]. These include tumour necrosis factor $\alpha(\mathrm{TNF}-\alpha)$ and interleukin (IL)-6, which contribute to insulin resistance, a major feature of T2D, and subsequent vascular dysfunction [5, 6]. Adipose tissue (AT) inflammation is orchestrated by innate lymphoid cells (ILCs) which also regulate various AT metabolic pathways [7]. However, their role in

(c) The Author(s). 2019 Open Access This article is distributed under the terms of the Creative Commons Attribution 4.0 International License (http://creativecommons.org/licenses/by/4.0/), which permits unrestricted use, distribution, and reproduction in any medium, provided you give appropriate credit to the original author(s) and the source, provide a link to the Creative Commons license, and indicate if changes were made. The Creative Commons Public Domain Dedication waiver (http://creativecommons.org/publicdomain/zero/1.0/) applies to the data made available in this article, unless otherwise stated. 
obesity and T2D is yet to be elucidated. ILCs are classified into three distinctive subgroups (ILC1/2/ and 3) based on the transcriptional factors and cytokines they produce. Contradictory findings on the role of ILCs in adipose tissue exist, with the various ILCs subtypes shown to promote inflammation and insulin resistance $[8,9]$ and, in contrast, improve insulin sensitivity and glucose metabolism [10].

Chronic hyperglycaemia as a consequence of insulin resistance and persistent secretion of inflammatory cytokines from visceral AT is associated with an increased cardiovascular risk in patients with T2D [11]. Pro-inflammatory cytokines which include IL-1/6 and TNF- $\alpha$ together with adhesion molecules exacerbate the inflammatory state and increase the risk of cardiovascular disease (CVD) in T2D [11]. To our knowledge, there are no available systematic reviews that have provided a synthesis of the role of ILCs in T2D and associated CVD risk stratification. Therefore, this systematic review will provide a comprehensive synthesis of available studies reporting on the role of ILCs and their associated analogues such as T helper cells in a T2D state. This study may also provide evidence-based insight into the bidirectional relationship of ILC activation and CVD risk in adults living with T2D.

\section{Objectives}

The objectives of the study are as follows:

1. To determine the activation levels of $\mathrm{T}$ helper cells in patients with T2D compared to healthy controls.

2. To determine the levels of ILCs in adipose tissue and peripheral blood of patients with T2D compared to healthy controls.

3. To evaluate the association between ILCs and traditional cardiovascular risk factors in patients with T2D.

\section{Methods}

This systemic review protocol has been prepared in accordance with Preferred Reporting Items for Systematic Review and Meta-Analysis Protocols 2015 guidelines [12].

\section{Systematic review registration}

The protocol has been registered with PROSPERO (CRD42018106159).

\section{Eligibility criteria}

Studies will be included based on the fulfilment of the following criteria.

\section{Study design}

This systematic review will include randomised clinical trials, observational studies, and case-control studies, with a clearly defined control population.
Participants The systematic review will mainly include studies reporting on adult obese T2D patients (over 18 years older).

Intervention The systematic review will include studies that report the use of oral glucose-lowering drugs.

Comparators T2D diabetic patients on treatment are compared to healthy controls.

Outcomes The study outcomes will include the following:

1. Primary outcomes

(a) ILC and CD4 T cell activation (reported as mean expression programmed cell death protein 1, CTLA4, major histocompatibility complex class-II (MHC-II), CD44 expression)

(b) CVD (reported as OR)

2. Surrogate outcomes

(a) The ratio of ILC subtypes (natural killer cells) and CD4 $\mathrm{T}$ cell cytokine levels (reported as mean TNF- $\alpha$, interferon gamma (INF- $\gamma$ ), IL-5, IL-6, and IL-13 levels)

(b) Cardiovascular risk (cholesterol, low-density lipoproteins, triglycerides)

\section{Search strategy}

A search strategy will be developed using Medical Subject Heading (MeSH) with keywords that include type 2 diabetes mellitus, innate lymphoid cells, natural killer cells, and $\mathrm{T}$ helper cells. The search strategy will be used to search the available electronic databases such as MEDLINE, Embase, Cochrane Collaboration, and ClinicalTrials.gov. The search strategy will be developed in consultation with a subject librarian. The systematic review will include studies published between the year 2000 and April 2019. The search will start from 2000 because ILCs were first discovered around that time period [7, 13]; however, a grouping of ILCs came in 2009 [14, 15]. The search will be restricted to available full-text without any language restriction. We will use the Mendeley referencing manager (V1.19.10) to remove duplicates. The bibliography of included studies will be screened for additional studies.

\section{Selection process}

Two independent reviewers (VM and BBN) will conduct the selection procedure. Each reviewer will screen the titles, abstracts, and full texts in contrast to the inclusion criteria. The reviewers will also exclude studies without available full texts and those reporting duplicate data from the same study cohort. The level of inter-rater agreement will be assessed using Cohen's kappa inter-rater reliability. 


\section{Data management Data items}

The reviewer (VM and BBN) will develop a data extraction form which will include the following data items: first author's name, year of publication, country, study design, sample size, age, gender, treatment used, duration of treatment, and experimental techniques used. Two reviewers (VM and TMN) will independently carry out the data extraction and also check for correctness of all extracted data items. The other author (BBN) will be consulted for arbitration in case of any disagreements.

\section{Data simplification}

Studies that report on various treatment interventions will be combined into a single group. In addition, studies reporting similar effect measures for ILC activation as well as $\mathrm{T}$ cell activation will be grouped.

\section{Risk of bias in individual studies}

To assess the potential risk of bias, the Downs and Black checklist will be used [16]. Two reviewers (VM and $\mathrm{BBN}$ ) will make independent judgments based on the four domains of the tool: reporting bias (10 items), external validity (3 items), internal validity (6 items), and selection bias (7 items). The scores will be rated as excellent (25-26), good (20-24), moderate (14-19), poor (11-13), and very poor $(<10)$. In case of disagreements, PVD will be consulted to arbitrate.

\section{Data synthesis}

If an efficient number of included studies are homogeneous in terms of study design and participant characteristics, we will use Review Manager V.5 to conduct a meta-analysis using a random effects model. Cochran's $Q$ and the $I^{2}$ statistic will be used to assess statistical heterogeneity between the included studies [17]. An $I^{2}$ value of $>25$ will be considered substantial heterogeneity [18]. To explore the sources of heterogeneity within the included studies, a subgroup analysis and meta-regression comparing the study estimates from different study-level characteristics will include the age, the gender of the study population, the study design and quality, the type of intervention, and the reported effect measure of ILC and $\mathrm{T}$ helper activation.

\section{Sensitivity analysis}

We will assess the potential sources of heterogeneity in studies with an $I^{2}>50$ by performing a sensitivity analysis and by omitting studies that are deemed as of high risk based on the risk of bias.

\section{Strength of evidence}

Two reviewers (VM and BBN) will assess the strength of evidence on the included studies using the Grading of
Recommendations Assessment, Development and Evaluation approach (GRADE) [19]. The quality of evidence will be assessed across the domains of risk of bias, consistency, directness, precision, and publication bias. The evidence of each outcome will be rated as either high, moderate, low, or very low. The GADEpro tool will be used to create a summary of findings (SoF) table.

\section{Discussion}

This systematic review and meta-analysis will provide a comprehensive synthesis of studies reporting on the activation levels and function of ILCs and T helper cells in T2D. This is part of a big study assessing the functional role of $\mathrm{T}$ cell activation and other inflammatory markers in metabolic diseases, especially those involving T2D and associated CVD complications [20, 21]. This review will also provide insights into the effects of anti-hyperglycaemic drugs on ILCs and T helper cells in T2D. This will therefore allow the identification of evidence gaps and also provide an evidence-based knowledge of associations between immune activation and T2DM.

\section{Abbreviations}

ILCs: Innate lymphoid cells; MeSH: Medical Subject Heading; NK cells: Natural killer cells; T2D: Type 2 diabetes mellitus; TNFa: Tumour necrosis factor alpha

\section{Authors' contributions}

VM, TMN, and BBN conceptualised and designed the study and drafted the protocol. VM, PVD, and BBN wrote and approved the final manuscript. VM is the guarantor of the review.

\section{Funding}

BBN is partially funded by the National Research Foundation of South Africa (grant number: 107519).

BBN is also University of KwaZulu Natal (UKZN) Developing Research Innovation, Localisation and Leadership in South Africa (DRILL) fellow. DRILL, is a HIH D43 grant (D43TW010131) awarded to UKZN in 2015 to support a research training and induction programme for early career academics. PVD was partially supported as a Post-Doctoral Fellow by funding from Research Capacity Division of the South African Medical Research Council (SAMRC).

The grand holder acknowledges that opinions, findings, and conclusions or recommendations expressed in any publication generated by NRF or SAMRC supported research are those of the authors, and that of the NRF accepts no liability whatsever in this regard.

\section{Ethics approval and consent to participate}

We will not be going out to collect raw data from subject but will be using or analysing data that has already published. Therefore, we will not be sought ethical clearance and consent from participants. All the above mentioned are not necessary in this case.

\section{Consent for publication}

None

\section{Competing interests}

The authors declare that they have no competing interests.

\section{Author details}

${ }^{1}$ School of Laboratory Medicine and Medical Sciences (SLMMS), College of Health Sciences, University of KwaZulu-Natal, Durban, South Africa. ${ }^{2}$ Department of Health Sciences, Faculty of Health and Applied Sciences, Namibia University of Science and Technology, Windhoek, Namibia. ${ }^{3}$ Department of Life and Environmental Science, Polytechnic University of Marche, Ancona, Italy. ${ }^{4}$ Biomedical Research and Innovation Platform, South African Medical Research Council, Tygerberg, South Africa. 
Received: 15 March 2019 Accepted: 15 August 2019

Published online: 03 September 2019

\section{References}

1. World Health Organisation/Fact sheets/Obesity and overweight [Internet]. [cited 2019 Mar 11]. Available from: https://www.who.int/en/news-room/ fact-sheets/detail/obesity-and-overweight

2. Domingueti CP, Dusse LMS, Carvalho M das G, de Sousa LP, Gomes KB, Fernandes AP. Diabetes mellitus: the linkage between oxidative stress, inflammation, hypercoagulability and vascular complications. J Diabetes Complications [Internet]. 2016 [cited 2018 May 7];30(4):738-745. Available from: http://linkinghub.elsevier.com/retrieve/pii/S1056872715005073

3. Patel PS, Buras EDBA. The role of the immune system in obesity and insulin resistance. J Obes. 2013:2013:1-9.

4. Wang M, Chen F, Wang J, Zeng Z, Yang Q, Shao S. Th17 and Treg lymphocytes in obesity and type 2 diabetic patients. Clin Immunol [Internet]. 2018;197(August):77-85. Available from: https://doi.org/10.1016/j. clim.2018.09.005

5. Kim SM, Lee SH, Kim YG, Kim SY, Seo JW, Choi YW, et al. Hyperuricemiainduced NLRP3 activation of macrophages contributes to the progression of diabetic nephropathy. Am J Physiol Ren Physiol [Internet]. 2015;308(9): F993-f1003. Available from: http://ajprenal.physiology.org/content/ajprenal/3 08/9/F993.full.pdf

6. Choe SS, Huh JY, Hwang IJ, Kim JI, Kim JB. Adipose tissue remodeling: its role in energy metabolism and metabolic disorders. Front Endocrinol (Lausanne). 2016;7:APR):1-16.

7. Cautivo KM, Molofsky AB. Regulation of metabolic health and adipose tissue function by group 2 innate lymphoid cells. Eur J Immunogenet. 2016:46: 1315-25.

8. Lu P, Ji X, Wan J, Xu H. Activity of group 2 innate lymphoid cells is associated with chronic inflammation and dysregulated metabolic homoeostasis in type 2 diabetic nephropathy. 2017;99-107.

9. $F$ Q, Wang $H$, Feng W, Ye $X$, Sun $X$, Jiang $C$, et al. ScienceDirect type 1 innate lymphoid cells are associated with type 2 diabetes. 2018;6-11.

10. Galle-treger L, Sankaranarayanan I, Hurrell BP, Howard E, Lo R, Maazi H, et al. Type 2 diabetes. Nat Commun [Internet] 2019;1-14. Available from: https:// doi.org/10.1038/s41467-019-08449-x

11. Margetic S. Review inflammation and. Haemostasis. 2012;22(1):49-62.

12. Moher $D$, Shamseer L, Clarke $M$, Ghersi $D$, Liberati $A$, Petticrew $M$, et al. Preferred reporting items for systematic review and meta-analysis protocols (PRISMA-P) 2015 statement. Syst Rev [Internet]. 2015:4(1):1-9. Available from: https://doi.org/10.1186/2046-4053-4-1\%5Cnhttp://www systematicreviewsjournal.com/content/4/1/1\%5CnAll Papers/M/Moher et al. 2015 - Preferred reporting items for systematic review and meta-analysis protocols (PRISMA-P) 2015 statement.pdf

13. Fort MM, Cheung J, Yen D, Li J, Zurawski SM, Lo S, et al. IL-25 Induces IL-4, IL-5, and IL-13 and Th2-associated pathologies in vivo. Immunity. 2001;15(6): 985-95.

14. Moro K, Yamada T, Tanabe M, Takeuchi T, Ikawa T, Kawamoto H, et al. Innate production of TH2 cytokines by adipose tissue-associated c-Kit+Sca1+lymphoid cells. Nature [Internet]. 2010;463(7280):540-544. Available from: https://doi.org/10.1038/nature08636

15. Miösberg JM, Trifari S, Crellin NK, Peters CP, Drunen CM Van, Piet B, et al. Human IL-25- and IL-33-responsive type 2 innate lymphoid cells are defined by expression of CRTH2 and CD161. 2011;12(11).

16. Downs SH, Black N. The feasibility of creating a checklist for the assessment of the methodological quality both of randomised and non-randomised studies of health care interventions. 1998:377-384.

17. Higgins JPT, Thompson SG, Deeks JJ, Altman DG. Measuring inconsistency in meta-analyses. BMJ Br Med J. 2003:327(7414):557-60.

18. Schroll JB, Moustgaard R, Gøtzsche PC. Dealing with substantial heterogeneity in Cochrane reviews. Cross-sectional study. 2011;

19. Group C, Synnot A, Glenton C, Cole S, Cumpston M. How to GRADE the quality of the evidence. CCCG Suppl Author Device [Internet]. 2016;1-24. Available from: http://cccrg.cochrane.org/author-resources
20. Nyambuya TM, Dludla PV, Nkambule BB. T cell activation and cardiovascular risk in type 2 diabetes mellitus: a protocol for a systematic review and meta-analysis. Syst Rev. 2018;7(1):1-6.

21. Nkambule BB, Mkandla Z, Mutize T, Dludla PV. Platelet function and cardiovascular risk in adult HIV-infected patients on HAART: a protocol for a systematic review and meta-analysis. BMJ Open [Internet]. 2017;7(12): e019468. Available from: https://doi.org/10.1136/bmjopen-2017-019468

\section{Publisher's Note}

Springer Nature remains neutral with regard to jurisdictional claims in published maps and institutional affiliations.
Ready to submit your research? Choose BMC and benefit from:

- fast, convenient online submission

- thorough peer review by experienced researchers in your field

- rapid publication on acceptance

- support for research data, including large and complex data types

- gold Open Access which fosters wider collaboration and increased citations

- maximum visibility for your research: over $100 \mathrm{M}$ website views per year

At BMC, research is always in progress.

Learn more biomedcentral.com/submission 